This manuscript was accepted at Psychology \& Health on 08/10/2018 in its current form. The Version of Record of this manuscript will be published and made available in Psychology \& Health, DOI: 10.1080/08870446.2018.1538451.

\title{
Parental Illness Intrusiveness and Youth Glycaemic Control in Type 1 Diabetes:
}

Intergenerational Associations and Processes

\author{
Sofie Prikken ${ }^{1,2}$, MSc \\ Leen Oris ${ }^{1,2}$, MSc \\ Jessica Rassart ${ }^{1,2}$, MSc \\ Lies Christine Missotten ${ }^{1}$, MSc \\ Ilse Weets ${ }^{3}, \mathrm{MD}, \mathrm{PhD}$ \\ Philip Moons ${ }^{1,4}, \mathrm{PhD}$ \\ Liesbet Goubert ${ }^{5}, \mathrm{PhD}$ \\ Koen Luyckx ${ }^{1,6}, \mathrm{PhD}$ \\ ${ }^{1}$ KU Leuven, Leuven, Belgium \\ ${ }^{2}$ Fonds Wetenschappelijk Onderzoek Vlaanderen \\ ${ }^{3}$ Free University Brussels, Brussels, Belgium \\ ${ }^{4}$ University of Gothenburg, Gothenburg, Sweden \\ ${ }^{5}$ Ghent University, Ghent, Belgium \\ ${ }^{6}$ UNIBS, University of the Free State, Bloemfontein, South Africa
}

Correspondence should be sent to Sofie Prikken, KU Leuven, Faculty of Psychology and Educational Sciences, Tiensestraat 102 - box 3717, 3000 Leuven, Belgium. Tel: 32 (0)16 37 42 53. Fax: 32 (0)16 3261 44. E-mail: sofie.prikken@kuleuven.be.

Funding: This work was supported by Research Council KU Leuven (grant C14/15/036 to Prof. Dr. Koen Luyckx), and by Research Foundation Flanders (grant G0B3514N to Prof. Dr. Koen Luyckx; grant 1126418N to Sofie Prikken).

Conflict of Interest: The authors declare that they have no conflict of interest.

Acknowledgments: The authors would like to thank Chris Groven and the Belgian Diabetes Registry for their help in collecting the data. 


\begin{abstract}
Objective. This study examined associations between the functioning of youth with type 1 diabetes and their parents, including parenting dimensions as intervening mechanisms. The study adds to the existing literature by focusing on (1) the concept of parental illness intrusiveness; (2) the (understudied) periods of adolescence and emerging adulthood; and (3) maternal and paternal functioning. Design. Questionnaires were completed by 317 patientmother dyads and 277 patient-father dyads. All patients (aged 14-25) had type 1 diabetes. The hypothesized model was compared to an alternative model using structural equation modelling.

Main Outcome Measures. Youth reported on depressive symptoms and treatment adherence; Physicians provided $\mathrm{HbA}_{1 \mathrm{c}}$-values. Parents reported on illness intrusiveness, depressive symptoms, and their child's treatment adherence. Patients and parents reported on psychological control and overprotection. Results. The hypothesized path model had a good fit to the data. Parental illness intrusiveness was positively associated with depressive symptoms and both were positively related to overprotection and psychological control. Psychological control was positively related to patients' depressive symptoms and negatively to treatment adherence. Poorer treatment adherence was associated with worse $\mathrm{HbA}_{1 \mathrm{c}}$-values. Conclusion. These findings underscore the relevance of parental illness intrusiveness and emphasize the importance of mothers' and fathers' roles throughout adolescence and emerging adulthood.
\end{abstract}

Key words: type 1 diabetes; contextual functioning; patient functioning; path analysis; intergenerational; parenting. 
Adolescence is traditionally considered a challenging period in which individuals have to address several normative developmental tasks, such as forming an independent identity. In industrialized countries, adolescents nowadays experience a prolonged period of self-focus and exploration before taking on adult roles, a period labelled emerging adulthood (ranging from 18 to 25 years of age; Arnett, 2000). For both adolescents and emerging adults, having a chronic illness may be accompanied by considerable challenges on top of their typical developmental tasks (Bryden et al., 2001).

Type 1 diabetes is a relatively common chronic illness that requires strict treatment behaviours, such as blood glucose monitoring and administering insulin. Integrating such behaviours into one's life can be challenging for adolescents and emerging adults, which is often reflected in deteriorating treatment adherence and glycaemic control (Bryden et al., 2001; Seiffge-Krenke, 2001). In these young people, depressive symptoms may be important in explaining such poorer illness outcomes (Johnson, Eiser, Young, Brierley, \& Heller, 2013). To counteract these outcomes, the family might play a substantial role. Indeed, Seiffge-Krenke (2001) emphasized the impact of type 1 diabetes on the family as well as the importance of parents in relation to illness management. When examining intergenerational functioning, the theoretical framework of Sherifali and Ciliska (2006), which was adapted from Belsky's seminal model on determinants of parenting (1984), might be particularly useful. This framework defines multiple determinants that influence parenting, that is, parent characteristics, child characteristics, and contextual factors. Given that parents of children with type 1 diabetes may experience more psychological distress (Whittemore, Jaser, Chao, Jang, \& Grey, 2012), the model's emphasis on contextual factors for explaining parental psychological functioning may offer new insights in this regard.

In general, former studies using such a familial approach mainly involved families with younger children. Older age groups, and particularly emerging adults, have received less 
attention. Despite the changes in parent-child relationships, parents remain important sources of support throughout adolescence and emerging adulthood (Helgeson et al., 2014). Hence, it is important to include emerging adults as well in research targeting family dynamics and intergenerational associations in type 1 diabetes.

\section{Parental Illness Intrusiveness}

As inspired by Sherifali and Ciliska's (2006) model, the concept of illness intrusiveness might provide new insights on parental functioning and its associations with youth functioning. Illness intrusiveness refers to the perception that a chronic illness interferes with daily activities, lifestyle, and interests (Devins et al., 1983). According to Fedele et al. (2012), parents of children with chronic illnesses have to engage in a long-term caregiving task. Caregiving responsibilities and illness demands may increase parents' feelings of being restraint or overwhelmed in their functioning at multiple levels (i.e., cognitive, emotional, behavioural) and among various life domains such as work, family relations, and self-expression or selfimprovement. Former findings have indeed demonstrated that these parents may experience illness intrusiveness and also subsequent psychological distress (Fedele et al., 2012).

To our knowledge, parental illness intrusiveness has not been examined yet in type 1 diabetes, although its utility has been confirmed in other populations such as juvenile rheumatic diseases (Andrews et al., 2009). Illness intrusiveness may inform our understanding of parental functioning, above and beyond the contributions of former research on related concepts such as paediatric parenting stress (Streisand, Braniecki, Tercyak, \& Kazak, 2001), caregiver strain (Carcone, Ellis, \& Naar-King, 2012), and parental diabetes-specific distress (Hessler, Fisher, Polonsky, \& Johnson, 2016). First, paediatric parenting stress refers to stress among parents caring for an ill child and contains four domains: communication, emotional functioning, medical care, and role functioning (Streisand et al., 2001). Especially this latter domain is related to illness intrusiveness, reflecting parents' experiences such as being able to go to work 
and having financial problems. However, most former studies do not differentiate between these different domains (e.g., Hansen, Weissbrod, Schwartz, \& Taylor, 2012). Moreover, illness intrusiveness taps into more specific life domains that are not covered by paediatric parenting stress (e.g., self-expression/self-improvement, health). Second, caregiver strain, defined as difficulties caregivers might experience when caring for a chronically ill child, comprises "psychic consequences of caring for children with special needs" (Brannan, Heflinger, \& Bickman, 1997), which may confound a clear distinction between perceived impact of the illness and resulting mental health symptoms. Again, some related life domains are explored, such as personal time, but illness intrusiveness assesses more diverse life domains. Third, parental diabetes-specific distress focuses on themes directly related to diabetes: personal distress, distress about the child's diabetes management, distress about the relationship with the child, and distress about the health care team (Hessler et al., 2016). Taken together, we would argue that, although these concepts share some characteristics, they clearly complement each other. Illness intrusiveness is important for understanding how chronic illness in youth impacts upon parents as it assesses possible disruptions in parents' personal lives among a wide array of life domains.

When investigating parental functioning, former studies mainly included mothers as primary caregivers, whereas fathers have been relatively neglected (Phares, Lopez, Fields, Kamboukos, \& Duhig, 2005). This is surprising given that Wysocki and Gavin (2006) stressed the importance of paternal involvement in illness management for adolescent functioning as well. Mothers and fathers may also experience similar levels of depressive symptoms (Hansen et al., 2012), which calls for a more in-depth investigation of paternal functioning.

\section{Parenting Dimensions as Intervening Mechanisms}

When relating parental to youth functioning, parenting is assumed to play a crucial role (Sherifali \& Ciliska, 2006). Traditionally, a typological approach has dominated parenting 
research. Different parenting styles were defined based on two dimensions: responsiveness refers to emotional support and empathy, whereas behavioural control (i.e., demandingness) refers to parental behaviours attempting to regulate or structure the child's behaviour (Barber, Stolz, Olsen, Collins, \& Burchinal, 2005; Baumrind, 1971). An authoritative parenting style (characterized by high scores on both dimensions) has been associated with the most optimal outcomes, as illustrated, for instance, by associations with better treatment adherence in youth with type 1 diabetes (Radcliff, Weaver, Chen, Streisand, \& Holmes, 2017).

During the past decades, research has increasingly focused on separate parenting dimensions instead of parenting styles, paving the way for other dimensions to be examined as well, such as psychological control and overprotection. Both dimensions impair psychological and behavioural autonomy development (Ellis, Templin, Naar - King, \& Frey, 2008; Holmbeck et al., 2002). Psychological control refers to parental control that intrudes upon the child's psychological and emotional development by means of criticism and guilt induction (Barber, 1996). It has been consistently associated with depressive symptoms in youth with and without type 1 diabetes (Barber, 1996; Butler, Skinner, Gelfand, Berg, \& Wiebe, 2007). Related constructs, such as hostile and critical parenting, have been linked to poorer glycaemic control in youth with type 1 diabetes (Jaser \& Grey, 2010). Overprotection constitutes an anxious parenting dimension, comprising protective behaviours that are excessive and developmentally inappropriate, such as feeling disproportionate concern for the child (Holmbeck et al., 2002; Thomasgard, Metz, Edelbrock, \& Shonkoff, 1995). Holmbeck et al. (2002) found overprotection to be linked to depressive symptoms and deviant and resistant behaviours in children with spina bifida. In type 1 diabetes, Seiffge-Krenke, Laursen, Dickson, and Hartl (2013) pointed to the possibility of poorer glycaemic control in families with high parental restrictiveness, although Bourdeau, Mullins, Carpentier, Colletti, and Wolfe-Christensen (2007) found that overprotection did not predict treatment adherence. In sum, although 
psychological control and overprotection have received significantly less attention than responsiveness and behavioural control, they might be of crucial importance in the context of type 1 diabetes (Young, Lord, Patel, Gruhn, \& Jaser, 2014).

Suboptimal parental functioning may be associated with maladaptive parenting (Sherifali \& Ciliska, 2006). Previous community research has indeed found that depressive mothers tend to respond less positively to their child, show more hostility and negativity, and are more coercive (Downey \& Coyne, 1990). In type 1 diabetes, Jaser, Whittemore, Ambrosino, Lindemann, and Grey (2008) observed that maternal depressive symptoms were related to less positive parenting. Similarly, Whittemore et al. (2012) reported that family disruption caused by type 1 diabetes was accompanied by elevated parental control. By integrating the aforementioned research findings, we were inspired by Eckshtain, Ellis, Kolmodin, and Naar King (2010) and Mackey et al. (2014) to examine whether maladaptive parenting dimensions would act as intervening mechanisms between parental and youth functioning.

\section{The Present Study}

The present multi-informant study builds upon former theorizing and research that examined intergenerational models linking parental functioning, parenting, and youth functioning (Eckshtain et al., 2010; Mackey et al., 2014; Sherifali \& Ciliska, 2006). Three contributions to the existing literature were anticipated. First, parental illness intrusiveness (Devins et al., 1983; Fedele et al., 2012) was examined, as it was expected to function as an important construct in explaining parental and youth functioning. Figure 1 outlines our hypothesized model. In this model, parental illness intrusiveness would relate positively to parental depressive symptoms (Fedele et al., 2012). Parental depressive symptoms, in turn, would be associated with psychological control and possibly overprotection (Jaser et al., 2008; Whittemore et al., 2012). Hence, parental depressive symptoms might partially explain associations between illness intrusiveness and maladaptive parenting. Next, both parenting dimensions would relate 
positively to youth depressive symptoms and negatively to treatment adherence (Butler et al., 2007; Jaser, 2011). Parental depressive symptoms were expected to relate to youth depressive symptoms as well (Whittemore et al., 2012). Finally, we expected that youth depressive symptoms would be associated with poorer treatment adherence and glycaemic control (Johnson et al., 2013).

Second, by including adolescents and emerging adults, we examined whether different intergenerational associations would occur among parental functioning, parenting dimensions, and patient functioning depending on developmental stage. In accordance with the increasing independence of emerging adults (Weissberg-Benchell, Wolpert, \& Anderson, 2007), we expected that parental illness intrusiveness would be more closely associated with adolescent functioning as compared to emerging adult functioning. Third, by including both mothers and fathers, we were able to compare patient-mother to patient-father dyads, accounting for the systematic underrepresentation of fathers in the current existing literature (Phares et al., 2005).

\section{Method}

\section{Participants and Procedure}

The present study is part of a larger project in which participants were recruited from the Belgian Diabetes Registry (BDR) using the following criteria: (1) diagnosed with type 1 diabetes, (2) between 14 and 25 years, and (3) Dutch speaking. Patients with impaired cognitive abilities were excluded $(N=5)$. A total of 1,450 patients, 1,447 mothers, and 1,441 fathers were eligible for participation and were sent informed consent forms and questionnaire packages; 53 envelopes were sent back unopened due to incorrect addresses. In total, 575 patients $(41.16 \%)$, 463 mothers (33.14\%), and 384 fathers (27.49\%) completed questionnaires. All participants signed an informed consent form and parents gave consent for minors. Four parental consents were lacking, resulting in 571 patient questionnaires. Non-responding participants received a reminder after four and eight weeks. A movie ticket was given to participating patients and 25 
dinner vouchers were distributed among parents. Only patients still living with their parents were included, resulting in 521 patients, 407 mothers, and 345 fathers. Patients without glycaemic control values were excluded, resulting in a final sample of 317 patient-mother and 277 patient-father dyads (of which 264 patients were included in both dyads).

Participants' characteristics are shown in Table 1. In patient-mother dyads, $48.73 \%$ of the patients were male and mean age was 17.93 (3.06). Insulin injections were used by $79.81 \%$ and mean illness duration was 6.78 (4.59) years. Mean $\mathrm{HbA}_{1 \mathrm{c}}$-values were 7.68\% (1.35). Youth reported that $76.97 \%$ of their parents were living together, while $17.67 \%$ of parents were divorced. Mothers' mean age was 47.07 (4.87). Among these mothers, 51.43\% obtained a higher education diploma and $81.96 \%$ were employed. In patient-father dyads, $48.91 \%$ of the patients were male and mean age was 17.97 (3.10). Insulin injections were used by $80.87 \%$ and mean illness duration was 6.73 (4.47) years. Mean $\mathrm{HbA}_{1 \mathrm{c}}$-values were $7.58 \%$ (1.09). Youth reported that $84.48 \%$ of their parents were living together and $11.91 \%$ were divorced. Fathers' mean age was 49.41 (5.50). Among these fathers, $49.82 \%$ obtained a higher education diploma and $88.37 \%$ were employed. In addition, the obtained $\mathrm{HbA}_{1 \mathrm{c}}$-values in both final samples were comparable to those in the overall diabetes population of this age group, registered at BDR between 2012 and 2016 (I. Weets, personal communication, August 11, 2016; $N=3,885$; median $=7.8 \%$ ).

\section{Measures}

\section{Illness Intrusiveness}

Mothers and fathers completed the Illness Intrusiveness Scale - Parent Version (Andrews et al., 2009), based on the validated Illness Intrusiveness Ratings Scale (Devins et al., 1983). This measure consists of 13 items addressing the impact of a child's illness on parents' personal life (e.g., work, financial status, relationship with spouse), with responses varying between 1 (not very much) and 7 (very much). Fedele et al. (2012) pointed to the validity of this measure in 
parents of children with juvenile rheumatic diseases. The items were translated to Dutch using the back-translation procedure (Chapman \& Carter, 1979). Sum scores were calculated, with higher scores indicating higher levels of illness intrusiveness. Cronbach's alphas were .91 for mothers and .92 for fathers.

Depressive Symptoms.

Mothers, fathers, and their children completed the Center for Epidemiologic Studies Depression Scale (CES-D; Bouma, 1995). This 20-item questionnaire assesses depressive symptoms during the past week, such as 'I had crying spells', with responses varying from 0 (Rarely or none of the time-less than 1 day) to 3 (Most or all of the time-3 to 7 days). The higher the respondents' total scores, the more experienced depressive symptoms. The CES-D has been validated in both adolescents and adults (Radloff, 1977, 1991) and has been widely used in diabetes research (e.g., Helgeson et al., 2014; Jaser et al., 2008). Cronbach's alphas were .75 for patients, .76 for mothers, and .71 for fathers.

Psychological Control.

Mothers, fathers, and their children completed the 8-item Psychological Control Scale-Youth Self-Report (Barber, 1996). Barber (1996) provided evidence for the validity of the original English version of the scale, and the current Dutch version has been used extensively as well (e.g., Luyckx, Soenens, Vansteenkiste, Goossens, \& Berzonsky, 2007). Items were answered on a 1 (Does not apply at all) to 5 (Strongly applies) Likert scale. Patients rated both mothers and fathers (e.g., My mother/father is less friendly to me if I don't see things like he/she does); parents reported on their own parenting (e.g., I tend to be less friendly to my son/daughter if he/she does not see things like I do). Mean scores were calculated, with higher scores indicating more psychological control. Cronbach's alphas were .78 and .75 for patients rating their mothers and fathers, respectively, .75 for mothers and .72 for fathers.

Overprotection. 
Mothers, fathers, and their children completed eight items assessing overprotection, including seven items of the Multidimensional Overprotective Parenting Scale (Kins \& Soenens, 2013) that has been recently validated in Dutch speaking adolescents (Brenning, Soenens, Van Petegem, \& Kins, 2017). One item of the adapted Egna Minnen Beträffande Uppfostran was also included, demonstrating good psychometric properties in both parent and adolescent versions (Castro, Pablo, Gómez, Arrindell, \& Toro, 1997; Gerlsma, Arrindell, van der Veen, \& Emmelkamp, 1991). Patients rated both parents (e.g., My mother/father immediately sees danger when I want to do something new); mothers and fathers reported on their own behaviours (e.g. I immediately see danger when my son/daughter wants to do something new). Items were answered on a 1 (Does not apply at all) to 5 (Strongly applies) Likert scale, with higher scores indicating more overprotective behaviour. Cronbach's alpha's were .81 and .78 for patients rating their mothers and fathers, respectively, .84 for mothers and .80 for fathers. (Due to a logistic error, some patients were unable to complete one specific item. Therefore, patients' Cronbach's alphas are based on the remaining seven items.)

\section{Treatment Adherence.}

Mothers, fathers, and their child completed the Self-Care Inventory (SCI; La Greca, Swales, Klemp, \& Madigan, 1988), a valid 14-item self-report questionnaire addressing patients' adherence to treatment regimens during the past month, such as blood glucose testing, and insulin and food regulation (Lewin et al., 2009). Participants were asked to indicate a response ranging from 1 (Never do it) to 5 (Always do this as recommended without fail), with the optional response 'Not applicable'. Mean scores were calculated, with higher scores indicating better treatment adherence. Item 12 'wearing a medic alert ID' is not common in Belgium and was left out. The SCI was translated to Dutch using the back-translation procedure (Chapman $\&$ Carter, 1979). Cronbach's alphas were .70 for patients, .77 for mothers, and .79 for fathers. Glycemic Control. 
After contacting treating physicians, we obtained patients' $\mathrm{HbA}_{1 \mathrm{c}}$-values closest to the date they completed the measures (within a time frame of three months before and after participation). $\mathrm{HbA}_{1 \mathrm{c}}$-values below $7.0 \%$ (adults) and $7.5 \%$ (adolescents) are recommended, with higher values indicating poorer glycaemic control (American Diabetes Association, 2016a, 2016b).

\section{Primary Statistical Analyses}

Primary analyses applied a structural equation modelling approach using Mplus 6. Maximum Likelihood Mean Variance was used as an estimation method to deal with non-normal data (Muthén \& Muthén, 1998-2012). Model fit was evaluated by (1) the $\chi^{2}$ index, which should be as small as possible, preferably non-significant; (2) the Root Mean Square Error of Approximation (RMSEA), which should be less than .08; (3) the Comparative Fit Index (CFI), which should exceed .90; and (4) the Standardized Root Mean Square Residual (SRMR), which should be less than .09 (Kline, 2005). Similar to Mackey et al. (2014), hybrid models including both observed and latent variables were estimated. Treatment adherence, psychological control, and overprotection were modelled as latent constructs, reported on by patients and mothers/fathers. Based on modification indices, error covariances reflecting shared method variance (e.g., between parental reports of overprotection and psychological control) were estimated (Kline, 2005). Patient age, gender, illness duration, and type of insulin administration (insulin pump vs. injections) were included as control variables by regressing all study variables on these variables (Seiffge-Krenke, 2001). To increase parsimony, all non-significant paths between control and study variables were omitted. The significance of indirect effects linking illness intrusiveness to glycaemic control was tested using the Model Indirect command in Mplus. To examine differences between adolescents (ages 14-17) and emerging adults (ages 18-25), multigroup analyses and $\chi^{2}$-difference tests using the DIFFTEST command in Mplus, were performed. In this procedure, a constrained model (with all structural paths set equal across age groups) was compared to an unconstrained model (with these paths allowed to vary). 
Because of the cross-sectional nature of the data, we compared our hypothesized model to an alternative patient-driven model (Kline, 2005), inspired by the work of Mackey et al. (2014). This alternative model started from patient functioning, with patient depressive symptoms, poorer treatment adherence, and poorer glycaemic control being related to parental illness intrusiveness. Parental illness intrusiveness, in turn, together with patient depressive symptoms, would be associated with parental depressive symptoms. In a last step, the parental functioning variables (i.e., illness intrusiveness and parental depressive symptoms) would be positively related to psychological control and overprotection. To compare the fit of both models, we used the Bayesian Information Criterion (BIC). A BIC-difference of 10 points or more was considered substantial, preferring the model with the lower BIC (Raftery, 1993).

\section{Results}

\section{Correlational Analyses}

Mean scores and correlations are displayed in Tables 2 and 3. Regarding patients' reports, depressive symptoms were positively related to psychological control, overprotection, and $\mathrm{HbA}_{1 \mathrm{c}}$-values, and negatively to treatment adherence. Psychological control was positively related to overprotection, and negatively to treatment adherence. Regarding parental reports, parental depressive symptoms were positively associated with illness intrusiveness, psychological control, and overprotection. In mothers, all of these variables related negatively to mothers' reports of treatment adherence, whereas in fathers, only psychological control and treatment adherence were negatively related. In both mothers and fathers, illness intrusiveness was positively related to psychological control and overprotection. Depressive symptoms in parents and youth were positively related.

\section{Primary Path Analyses}

Patient-mother Dyads. 
The model displayed in Figure 1 (including error covariances between parent reports of psychological control and overprotection and of treatment adherence and psychological control, and between adolescent reports of overprotection and psychological control) had an adequate fit $\left[\chi^{2}(34)=80.555, p<.001 ; \mathrm{RMSEA}=.066 ; \mathrm{CFI}=.918 ; \mathrm{SRMR}=.038\right]$. For reasons of parsimony, all non-significant paths from patient age, gender, illness duration, and type of insulin administration were omitted, resulting in the final model that retained a good fit $\left[\chi^{2}(54)\right.$ $=98.643, p<.001 ; \mathrm{RMSEA}=.051 ; \mathrm{CFI}=.922 ; \mathrm{SRMR}=.043]$. Concerning these control variables, girls reported more depressive symptoms $(\beta=.18 ; p<.001)$. Patient age was negatively related to treatment adherence $(\beta=-.22 ; p<.001)$ and $\mathrm{HbA}_{1 \mathrm{c}}$-values $(\beta=-.17 ; p<$ $.001)$, and positively to maternal depressive symptoms $(\beta=.10 ; p=.044)$. Illness duration was negatively related to treatment adherence $(\beta=-.16 ; p=.003)$ and positively to overprotection $(\beta=.13 ; p=.030)$ and illness intrusiveness $(\beta=.21 ; p<.001)$. Having an insulin pump was related to less overprotection $(\beta=-.19 ; p=.001)$. The final model is displayed in Figure 2, except for the paths from control to study variables. Standardized coefficients for patientmother dyads are displayed before the slash. In line with expectations about parental functioning, parental illness intrusiveness was positively associated with parental depressive symptoms. As expected, these parental functioning indicators were positively related to the parenting dimensions of overprotection and psychological control. When relating these parenting dimensions to patient functioning, only psychological control showed significant results, being positively related to patient depressive symptoms and negatively to treatment adherence. With respect to patient functioning, depressive symptoms were negatively related to treatment adherence, which, in turn, was negatively related to $\mathrm{HbA}_{1 c}$. In sum, all of the hypothesized paths were confirmed, except for the paths from overprotection to patient depressive symptoms and treatment adherence, and from patient depressive symptoms to $\mathrm{HbA}_{1 \mathrm{c}}$. The sum of indirect effects linking illness intrusiveness to glycaemic control (point 
estimate $=.107$, S.E. $=.039)$ was significant at $p=.006$. Finally, when comparing adolescents to emerging adults, the multigroup analysis did not reveal significant differences between the constrained and the unconstrained model $\left[\Delta \chi^{2}(14)=22.203 ; p=.075\right]$, suggesting that the model fitted equally well for adolescents and emerging adults.

\section{Patient-father Dyads.}

The hypothesized model (including error covariances between parent reports of overprotection and psychological control and of treatment adherence and psychological control) had an adequate fit $\left[\chi^{2}(37)=65.199, p=.003 ; \mathrm{RMSEA}=.053 ; \mathrm{CFI}=.922 ; \mathrm{SRMR}=.042\right]$. For reasons of parsimony, all non-significant paths from the control variables were again omitted, resulting in the final model that retained a good fit $\left[\chi^{2}(47)=73.453, p=.008\right.$; RMSEA $=.045$; CFI $=$ $.929 ;$ SRMR $=.046]$. Regarding these control variables, girls reported more depressive symptoms $(\beta=.15 ; p=.005)$. Patient age was negatively related to $\mathrm{HbA}_{1 c}$-values $(\beta=-.13 ; p$ $=.016)$. Illness duration was negatively related to treatment adherence $(\beta=-.25 ; p<.001)$ and paternal depressive symptoms $(\beta=-.15 ; p=.005)$. The final model is shown in Figure 2, with the standardized coefficients for patient-father dyads displayed after the slash. In line with expectations about parental functioning, parental illness intrusiveness was positively associated with parental depressive symptoms. When relating parental functioning to parenting dimensions, both parental illness intrusiveness and parental depressive symptoms were positively related to overprotection. Contrary to expectations, only depressive symptoms were associated with psychological control. When linking these parenting dimensions to patient functioning, only psychological control showed significant results, being positively related to patient depressive symptoms and negatively to treatment adherence. With respect to patient functioning, depressive symptoms were negatively related to treatment adherence, which, in turn, was negatively associated with $\mathrm{HbA}_{1 \mathrm{c}}$. The sum of indirect effects linking illness intrusiveness to glycaemic control (point estimate $=.061$, S.E. $=.022$ ) was significant at $p=$ 
.005. In sum, all of the hypothesized associations were confirmed, except for the paths from illness intrusiveness to psychological control, from parental depressive symptoms to patient depressive symptoms, from overprotection to patient depressive symptoms and treatment adherence, and from patient depressive symptoms to $\mathrm{HbA}_{1 \mathrm{c}}$. Finally, when comparing adolescents to emerging adults, the multigroup analysis did not reveal significant differences between the constrained and the unconstrained model $\left[\Delta \chi^{2}(14)=13.657 ; p=.476\right]$, suggesting that the model fitted equally well for adolescents and emerging adults.

\section{Alternative Model Testing}

In patient-mother dyads, our alternative model (including the same paths from control to study variables as the hypothesised model) was not accompanied by an adequate fit across all indices $\left[\chi^{2}(55)=125.016, p<.001 ; \mathrm{RMSEA}=.063 ; \mathrm{CFI}=.877 ; \mathrm{SRMR}=.064\right]$, and BIC preferred the hypothesized model to this alternative model $(\mathrm{BIC}=10086.646$ vs. 10118.421, respectively). In patient-father dyads, the alternative model had an adequate fit $\left[\chi^{2}(50)=84.888\right.$, $p=.002 ; \mathrm{RMSEA}=.050 ; \mathrm{CFI}=.901 ; \mathrm{SRMR}=.060]$, but $\mathrm{BIC}$ again preferred the hypothesised model (BIC $=9064.244$ vs. 9890.466 , respectively). Taken together, the hypothesized model was preferred to the alternative patient-driven model in patient-mother and patient-father dyads.

\section{Discussion}

The present multi-informant study investigated an intergenerational model integrating aspects of parental functioning, parenting dimensions, and patient functioning in families of youth with type 1 diabetes. In doing so, we were inspired by the theoretical framework of Sherifali and Ciliska (2006). We examined parental illness intrusiveness as well as parental depressive symptoms and how they were associated with youth functioning (both illness-specific and psychosocial). Before interpreting more specific findings resulting from our model, three general conclusions merit attention. First, our parent-driven theoretical model fitted the data better than the alternative patient-driven model, indicating that parental functioning may indeed 
constitute an important predictor of youth functioning. Second, the results were highly similar in patient-mother and patient-father dyads, confirming that both maternal and paternal functioning are related to child functioning. Third, this study testifies to the continued importance of parents during adolescence and emerging adulthood, despite the increasing independence and changing parent-child relationships in the transition to adulthood.

\section{Parental Functioning and Parenting Dimensions}

After being examined in juvenile rheumatic diseases (Fedele et al., 2012), the present study demonstrated the relevance of parental illness intrusiveness in type 1 diabetes. Using this concept, we shed light on how the notion of type 1 diabetes as a family disease may translate into daily life. In line with expectations, illness intrusiveness was positively associated with depressive symptoms in mothers and fathers. However, it remains unclear whether illness intrusiveness actually leads to elevated depressive symptoms or whether this relationship is bidirectional. Earlier research has suggested that the experienced burden of diabetes management may mediate the association between caregiver depressive symptoms and adolescent glycaemic control (Cunningham, Vesco, Dolan, \& Hood, 2011). This would imply that depressive symptoms may also set the stage for experiencing illness intrusiveness, which should be investigated longitudinally.

Parental illness intrusiveness and depressive symptoms were associated with overprotection and psychological control. Regarding psychological control, these findings match those of previous studies (Epkins \& Harper, 2016). Regarding overprotection, previous studies reported inconsistent findings, with parental depressive symptoms being related to less (Eckshtain et al., 2010) but also to more -although less efficient- involvement (Wiebe et al., 2011). Our results are in line with the latter study, given that overprotection consists of anxious and intrusive behaviours. Overprotection might be due to increased feelings of uncertainty and incompetence possibly accompanying depressive symptoms. Interestingly, insulin pump use 
was associated with less overprotection, suggesting that these technologies may provide parents some release in terms of anxiousness. In sum, when parents experience the illness of their child as highly intrusive and as interfering with their personal life, this could set the stage for parental depressive symptoms and, subsequently, for a suboptimal family climate.

\section{The Role of the Parents in Patient Functioning}

Parental functioning was expected to predict patient functioning, both directly and indirectly through the parenting dimensions of psychological control and overprotection. Consistent with previous findings (Jaser et al., 2008), the direct pathway linking parental to patient depressive symptoms was significant in patient-mother dyads. Regarding the indirect pathway linking parental to patient functioning, both psychological control and overprotection were expected to predict patient functioning. Concerning psychological control, our findings were in line with previous studies (e.g., Butler et al., 2007), that found psychological control to be related to more depressive symptoms and poorer treatment adherence in youth. According to Barber et al. (2005), this might be due to the intrusive nature of psychological control, hindering youth in becoming psychologically autonomous. Overprotection was not uniquely associated with patient functioning, although the correlational analyses revealed overprotection to be positively associated with patient depressive symptoms. Overprotection is generally considered a maladaptive parenting dimension that might be more prevalent in chronic illnesses (Holmbeck et al., 2002), but its adverse associations have not been consistently demonstrated in previous research (e.g., Bourdeau et al., 2007). As a possible explanation, Muris, Meesters, and van Brakel (2003) have suggested that overprotection might also be positively motivated, resulting from a concern for the well-being of one's child. Overprotective behaviours may hence be implemented in a rather warm, responsive family, which could possibly explain the rather unexpected findings. In general, especially psychological control seemed detrimental towards youth functioning, although further research is needed to identify specific determinants and 
consequences of psychological control, as well as to clarify the concept of overprotection and its unique developmental consequences (Ellis et al., 2008).

Regarding youth functioning, another unexpected finding was revealed, that is, the lack of associations between patient depressive symptoms and glycaemic control. The correlational analyses, however, showed significant relations between depressive symptoms and poorer glycaemic control. Based on a meta-analysis reporting that treatment nonadherence constitutes an important pathway linking depressive symptoms to clinical outcomes (Gonzalez et al., 2008), treatment adherence might have acted as an intervening mechanism between depressive symptoms and glycaemic control, which should be examined longitudinally in future research.

\section{Limitations and Future Suggestions}

Several limitations need to be considered. First, although an alternative patient-driven model was tested, no definite conclusions can be drawn on directionality of effects due to our crosssectional design. Longitudinal studies should investigate, for instance, whether parenting dimensions would also predict parental functioning over time or whether poorer treatment adherence would result in greater parental illness intrusiveness. Second, the sample consisted predominantly of Belgian, Dutch-speaking participants, constituting a relatively homogenous sample and possibly hindering generalization to other populations. Due to the relatively low response rate, a potential selection bias could also not be excluded. Additionally, by only including adolescents and emerging adults living with their parents, we might have limited the generalizability of the current findings, keeping in mind that the functioning of those living independently might be less strongly associated with the functioning of their parents. Finally, our study was mainly questionnaire-based. Although these instruments are appropriate to measure internal processes, in-depth measurements should be used in the future to validate the current findings. For instance, when examining treatment adherence, multi-dimensional 
measurements should be used, tapping into individual treatment behaviours to improve the specificity of the obtained findings.

\section{Clinical Implications}

Important intergenerational associations between parental and patient functioning were demonstrated, with parental illness intrusiveness constituting a crucial variable. The family context may serve a supportive function not only for younger children, as parents should continue their supportive role for adolescents and emerging adults as well (Monaghan, Helgeson, \& Wiebe, 2015). Accordingly, both adolescents and emerging adults may benefit from family-based interventions (Wysocki et al., 2006). Further, our findings suggest that mothers and fathers should be explicitly included in research and clinical practice to gain a balanced perspective on the adaptation of parents and children. To conclude, we encourage that parental functioning should be assessed together with youth functioning during regular hospital visits, and that psychological support must be given to all family members who express difficulties due to the illness. 


\section{References}

American Diabetes Association. (2016a). Children and adolescents. Diabetes Care, 39, S86S93.

American Diabetes Association. (2016b). Glycemic targets. Diabetes Care, 39, S39-S46.

Andrews, N. R., Chaney, J. M., Mullins, L. L., Wagner, J. L., Hommel, K. A., \& Jarvis, J. N. (2009). The differential effect of child age on the illness intrusiveness-parent distress relationship in juvenile rheumatic disease. Rehabilitation Psychology, 54, 45-50.

Arnett, J. J. (2000). Emerging adulthood. American Psychologist, 55, 469-480.

Barber, B. K. (1996). Parental psychological control: Revisiting a neglected construct. Child Development, 67, 3296-3319.

Barber, B. K., Stolz, H. E., Olsen, J. A., Collins, W. A., \& Burchinal, M. (2005). Parental support, psychological control, and behavioral control: Assessing relevance across time, culture, and method. Monographs of the Society for Research in Child Development, 70 , i-147.

Baumrind, D. (1971). Current patterns of parental authority. Developmental Psychology, 4, 1102.

Belsky, J. (1984). The determinants of parenting: A process model. Child Development, 8396.

Bouma, J. (1995). Het meten van symptomen van depressie met de ces-d: Een handleiding [the measurement of symptoms of depression with the cesd: A manual]. Noordelijk Centrum voor Gezondheidsvraagstukken, Rijksuniversiteit Groningen.

Bourdeau, T., Mullins, L., Carpentier, M., Colletti, C., \& Wolfe-Christensen, C. (2007). An examination of parenting variables and child self-care behavior across disease groups. Journal of Developmental and Physical Disabilities, 19, 125-134. 
Brannan, A. M., Heflinger, C. A., \& Bickman, L. (1997). The caregiver strain questionnaire: Measuring the impact on the family of living with a child with serious emotional disturbance. Journal of Emotional and Behavioral Disorders, 5, 212-222.

Brenning, K. M., Soenens, B., Van Petegem, S., \& Kins, E. (2017). Searching for the roots of overprotective parenting in emerging adulthood: Investigating the link with parental attachment representations using an actor partner interdependence model (apim). Journal of Child and Family Studies, 26, 2299-2310.

Bryden, K. S., Peveler, R. C., Stein, A., Neil, A., Mayou, R. A., \& Dunger, D. B. (2001). Clinical and psychological course of diabetes from adolescence to young adulthood: A longitudinal cohort study. Diabetes Care, 24, 1536-1540.

Butler, J. M., Skinner, M., Gelfand, D., Berg, C. A., \& Wiebe, D. J. (2007). Maternal parenting style and adjustment in adolescents with type i diabetes. Journal of Pediatric Psychology, 32, 1227-1237.

Carcone, A. I., Ellis, D. A., \& Naar-King, S. (2012). Linking caregiver strain to diabetes illness management and health outcomes in a sample of adolescents in chronically poor metabolic control. Journal of Developmental and Behavioral Pediatrics, 33, 343 351.

Castro, J., Pablo, J., Gómez, J., Arrindell, W., \& Toro, J. (1997). Assessing rearing behaviour from the perspective of the parents: A new form of the embu. Social Psychiatry and Psychiatric Epidemiology, 32, 230-235.

Chapman, D. W., \& Carter, J. F. (1979). Translation procedures for the cross cultural use of measurement instruments. Educational Evaluation and Policy Analysis, 1, 71-76.

Cunningham, N. R., Vesco, A. T., Dolan, L. M., \& Hood, K. K. (2011). From caregiver psychological distress to adolescent glycemic control: The mediating role of perceived burden around diabetes management. Journal of Pediatric Psychology, 36, 196-205. 
Devins, G. M., Binik, Y. M., Hutchinson, T. A., Hollomby, D. J., Barré, P. E., \& Guttmann, R. D. (1983). The emotional impact of end-stage renal disease: Importance of patients' perceptions of intrusiveness and control. International Journal of Psychiatry in Medicine, 13, 327-343.

Downey, G., \& Coyne, J. C. (1990). Children of depressed parents: An integrative review. Psychological Bulletin, 108, 50-76.

Eckshtain, D., Ellis, D. A., Kolmodin, K., \& Naar - King, S. (2010). The effects of parental depression and parenting practices on depressive symptoms and metabolic control in urban youth with insulin dependent diabetes. Journal of Pediatric Psychology, 35, 426-435.

Ellis, D. A., Templin, T. N., Naar - King, S., \& Frey, M. A. (2008). Toward conceptual clarity in a critical parenting construct: Parental monitoring in youth with chronic illness. Journal of Pediatric Psychology, 33, 799-808.

Epkins, C. C., \& Harper, S. L. (2016). Mothers' and fathers' parental warmth, hostility/ rejection/ neglect, and behavioral control: Specific and unique relations with parents' depression versus anxiety symptoms. Parenting-Science and Practice, 16, 125-145.

Fedele, D. A., Ryan, J. L., Ramsey, R. R., Grant, D. M., Bonner, M. S., Stermer, S. P., . . Chaney, J. M. (2012). Utility of the illness intrusiveness scale in parents of children diagnosed with juvenile rheumatic diseases. Rehabilitation Psychology, 57, 73-80.

Gerlsma, C., Arrindell, W. A., van der Veen, N., \& Emmelkamp, P. M. G. (1991). A parental rearing style questionnaire for use with adolescents: Psychometric evaluation of the embu-a. Personality and Individual Differences, 12, 1245-1253.

Gonzalez, J. S., Peyrot, M., McCarl, L. A., Collins, E. M., Serpa, L., Mimiaga, M. J., \& Safren, S. A. (2008). Depression and diabetes treatment nonadherence: A metaanalysis. Diabetes Care, 31, 2398-2403. 
Hansen, J. A., Weissbrod, C., Schwartz, D. D., \& Taylor, W. P. (2012). Paternal involvement in pediatric type 1 diabetes: Fathers' and mothers' psychological functioning and disease management. Families, Systems, \& Health, 30, 47-59.

Helgeson, V. S., Palladino, D. K., Reynolds, K. A., Becker, D. J., Escobar, O., \& Siminerio, L. (2014). Relationships and health among emerging adults with and without type 1 diabetes. Health Psychology, 33, 1125-1133.

Hessler, D., Fisher, L., Polonsky, W., \& Johnson, N. (2016). Understanding the areas and correlates of diabetes-related distress in parents of teens with type 1 diabetes. Journal of Pediatric Psychology, 41, 750-758.

Holmbeck, G. N., Johnson, S. Z., Wills, K. E., McKernon, W., Rose, B., Erklin, S., \& Kemper, T. (2002). Observed and perceived parental overprotection in relation to psychosocial adjustment in preadolescents with a physical disability: The mediational role of behavioral autonomy. Journal of Consulting and Clinical Psychology, 70, 96110.

Jaser, S. S. (2011). Family interaction in pediatric diabetes. Current Diabetes Reports, 11, 480-485.

Jaser, S. S., \& Grey, M. (2010). A pilot study of observed parenting and adjustment in adolescents with type 1 diabetes and their mothers. Journal of Pediatric Psychology, $35,738-747$.

Jaser, S. S., Whittemore, R., Ambrosino, J. M., Lindemann, E., \& Grey, M. (2008). Mediators of depressive symptoms in children with type 1 diabetes and their mothers. Journal of Pediatric Psychology, 33, 509-519.

Johnson, B., Eiser, C., Young, V., Brierley, S., \& Heller, S. (2013). Prevalence of depression among young people with type 1 diabetes: A systematic review. Diabetic Medicine, 30, 199-208. 
Kins, E., \& Soenens, B. (2013). Generation me and its helicopter parents. Paper presented at 16th European Conference on Developmental Psychology. Lausanne, Switzerland.

Kline, R. B. (2005). Principles and practices of structural equation modelling (2 ed.). New York: Guilford Press.

La Greca, A. M., Swales, T., Klemp, S., \& Madigan, S. (1988). Self care behaviors among adolescents with diabetes (abstract). Presented at 9th Annual Sessions of the Society of Behavioral Medicine (pp. A42). Baltimore, MD: Society of Behavioral Medicine.

Lewin, A. B., Lagreca, A. M., Geffken, G. R., Williams, L. B., Duke, D. C., Storch, E. A., \& Silverstein, J. H. (2009). Validity and reliability of an adolescent and parent rating scale of type 1 diabetes adherence behaviors: The self-care inventory (sci). Journal of Pediatric Psychology, 34, 999-1007.

Luyckx, K., Soenens, B., Vansteenkiste, M., Goossens, L., \& Berzonsky, M. D. (2007). Parental psychological control and dimensions of identity formation in emerging adulthood. Journal of Family Psychology, 21, 546-550.

Mackey, E. R., Struemph, K., Powell, P. W., Chen, R., Streisand, R., \& Holmes, C. S. (2014). Maternal depressive symptoms and disease care status in youth with type 1 diabetes. Health Psychology, 33, 783-791.

Monaghan, M., Helgeson, V., \& Wiebe, D. (2015). Type 1 diabetes in young adulthood. Current Diabetes Reviews, 11, 239-250.

Muris, P., Meesters, C., \& van Brakel, A. (2003). Assessment of anxious rearing behaviors with a modified version of "egna minnen beträffande uppfostran" questionnaire for children. Journal of Psychopathology and Behavioral Assessment, 25, 229-237.

Muthén, L. K., \& Muthén, B. O. (1998-2012). Mplus user's guide (7 ed.). Los Angeles, CA: Muthén \& Muthén. 
Phares, V., Lopez, E., Fields, S., Kamboukos, D., \& Duhig, A. M. (2005). Are fathers involved in pediatric psychology research and treatment? Journal of Pediatric Psychology, 30, 631-643.

Radcliff, Z., Weaver, P., Chen, R., Streisand, R., \& Holmes, C. (2017). The role of authoritative parenting in adolescent type 1 diabetes management. Journal of Pediatric Psychology, 1-10.

Radloff, L. S. (1977). The ces-d scale: A self-report depression scale for research in the general population. Applied Psychological Measurement, 1, 385-401.

Radloff, L. S. (1991). The use of the center for epidemiologic studies depression scale in adolescents and young adults. Journal of Youth and Adolescence, 20, 149-166.

Raftery, A. E. (1993). Bayesian model selection in structural equation models. In K. Bollen \& J. Long (Eds.), Testing structural equation models (pp. 163-180). Newbury Park, CA: Sage

Seiffge-Krenke, I. (2001). Diabetic adolescents and their families: Stress, coping, and adaptation: Cambridge University Press.

Seiffge-Krenke, I., Laursen, B., Dickson, D. J., \& Hartl, A. C. (2013). Declining metabolic control and decreasing parental support among families with adolescents with diabetes: The risk of restrictiveness. Journal of Pediatric Psychology, 38, 518-530.

Sherifali, D., \& Ciliska, D. (2006). Parenting children with diabetes and belsky's determinants of parenting model: Literature review. Journal of Advanced Nursing, 55, 636-642.

Streisand, R., Braniecki, S., Tercyak, K. P., \& Kazak, A. E. (2001). Childhood illness-related parenting stress: The pediatric inventory for parents. Journal of Pediatric Psychology, $26,155-162$.

Thomasgard, M., Metz, W. P., Edelbrock, C., \& Shonkoff, J. P. (1995). Parent-child relationship disorders. Part i. Parental overprotection and the development of the 
parent protection scale. Journal of Developmental and Behavioral Pediatrics, 16, 244250.

Weissberg-Benchell, J., Wolpert, H., \& Anderson, B. J. (2007). Transitioning from pediatric to adult care: A new approach to the post-adolescent young person with type 1 diabetes. Diabetes Care, 30, 2441-2446.

Whittemore, R., Jaser, S., Chao, A., Jang, M., \& Grey, M. (2012). Psychological experience of parents of children with type 1 diabetes. Diabetes Educator, 38, 562-579.

Wiebe, D. J., Gelfand, D., Butler, J. M., Korbel, C., Fortenberry, K. T., McCabe, J. E., \& Berg, C. A. (2011). Longitudinal associations of maternal depressive symptoms, maternal involvement, and diabetes management across adolescence. Journal of Pediatric Psychology, 36, 837-846.

Wysocki, T., \& Gavin, L. (2006). Paternal involvement in the management of pediatric chronic diseases: Associations with adherence, quality of life, and health status. Journal of Pediatric Psychology, 31, 501-511.

Wysocki, T., Harris, M. A., Buckloh, L. M., Mertlich, D., Lochrie, A. S., Taylor, A., . . White, N. H. (2006). Effects of behavioral family systems therapy for diabetes on adolescents' family relationships, treatment adherence, and metabolic control. Journal of Pediatric Psychology, 31, 928-938.

Young, M., Lord, J., Patel, N., Gruhn, M., \& Jaser, S. (2014). Good cop, bad cop: Quality of parental involvement in type 1 diabetes management in youth. Current Diabetes Reports, 14, 1-12. 
Table 1

Demographic and Clinical Characteristics of Patients and Parents

Patient-mother dyads $(n=317)$

Patient-father dyads $(n=277)$

$M(S D)$

$M(S D)$

\begin{tabular}{|c|c|c|}
\hline \multicolumn{3}{|l|}{ Patient } \\
\hline \multicolumn{3}{|l|}{$\operatorname{Sex}^{1}$} \\
\hline Male & $154(48.73 \%)$ & $135(48.91 \%)$ \\
\hline Female & $162(51.27 \%)$ & $141(51.09 \%)$ \\
\hline Age & $17.93(3.06)$ & $17.97(3.10)$ \\
\hline Insulin injection ${ }^{1}$ & $253(79.81 \%)$ & $224(80.87 \%)$ \\
\hline \multicolumn{3}{|l|}{ Family Structure ${ }^{1}$} \\
\hline Parents married/living together & $244(76.97 \%)$ & $234(84.48 \%)$ \\
\hline Parents divorced & $56(17.67 \%)$ & $33(11.91 \%)$ \\
\hline Parent deceased & $2(0.63 \%)$ & l \\
\hline Stepparent & $15(4.73 \%)$ & $10(3.61 \%)$ \\
\hline Illness duration & $6.78(4.59)$ & $6.73(4.47)$ \\
\hline $\mathrm{HbA}_{1 \mathrm{c}} \%$ & $7.68(1.35)$ & $7.58(1.09)$ \\
\hline \multicolumn{3}{|l|}{ Parent } \\
\hline Age & $47.07(4.87)$ & $49.41(5.50)$ \\
\hline \multicolumn{3}{|l|}{ Educational level $^{1}$} \\
\hline$\leq$ Secondary School & $153(48.57 \%)$ & $138(50.18 \%)$ \\
\hline$\geq$ Higher education & $162(51.43 \%)$ & $137(49.82 \%)$ \\
\hline \multicolumn{3}{|l|}{ Employment $^{1}$} \\
\hline Employed & $259(81.96 \%)$ & $243(88.37 \%)$ \\
\hline Not employed & $44(13.92 \%)$ & $14(5.06 \%)$ \\
\hline
\end{tabular}

Note. ${ }^{1}$ Displayed as numbers and percentages (between brackets). 
Table 2

Mean Scores and Standard Deviations on Study Variables

\begin{tabular}{|c|c|c|c|c|}
\hline & $\begin{array}{l}\text { Patients (mother dyads) } \\
\qquad(n=317)\end{array}$ & $\begin{array}{l}\text { Mothers } \\
(n=317)\end{array}$ & $\begin{array}{l}\text { Patients (father dyads) } \\
\qquad(n=277)\end{array}$ & $\begin{array}{l}\text { Fathers } \\
(n=277)\end{array}$ \\
\hline & $M(S D)$ & $M(S D)$ & $M(S D)$ & $M(S D)$ \\
\hline Illness intrusiveness & l & $31.38(14.78)$ & l & $26.80(13.51)$ \\
\hline Depressive symptoms & $11.18(10.33)$ & $10.25(8.70)$ & $11.02(10.28)$ & $7.62(7.71)$ \\
\hline Psychological control & $2.11(0.71)$ & $2.03(0.63)$ & $2.02(0.65)$ & $2.08(0.59)$ \\
\hline Overprotection & $2.88(0.88)$ & $2.70(0.88)$ & $2.43(0.74)$ & $2.38(0.76)$ \\
\hline Treatment Adherence & $3.82(0.49)$ & $3.91(0.55)$ & $3.84(0.48)$ & $3.99(0.53)$ \\
\hline
\end{tabular}


Table 3

Correlations between Study Variables in Patient-Mother and Patient-Father Dyads

\begin{tabular}{|c|c|c|c|c|c|c|c|c|c|c|c|}
\hline & & 1 & 2 & 3 & 4 & 5 & 6 & 7 & 8 & 9 & 10 \\
\hline \multirow{5}{*}{ 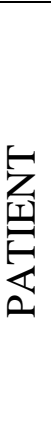 } & 1. Depressive symptoms & - & $.44 * * *$ & $.22 * * *$ & $-.34 * * *$ & $.21 * * *$ & $.28 * * *$ & $.25 * * *$ & $.17 * *$ & $.12 *$ & $-.27 * * *$ \\
\hline & 2. Psychological control & $.24 * * *$ & - & $.42 * * *$ & $-.29 * * *$ & $.23 * * *$ & $.16^{* *}$ & $.24 * * *$ & $.41 * * *$ & $.20 * * *$ & $-.26 * * *$ \\
\hline & 3. Overprotection & $.22 * * *$ & $.34 * * *$ & - & -.05 & .04 & $.15^{* *}$ & $.19 * *$ & $.19 * *$ & $.46 * * *$ & $-.12 *$ \\
\hline & 4. Treatment adherence & $-.24 * * *$ & $-.19 * *$ & -.04 & - & $-.29 * * *$ & $-.12 *$ & -.06 & $-.13^{*}$ & -.06 & $.59 * * *$ \\
\hline & 5. $\mathrm{HbA}_{1 \mathrm{c}}$ & $.18 * *$ & .06 & .05 & $-.25 * * *$ & - & .09 & $.16^{* *}$ & .09 & .04 & $-.39 * * *$ \\
\hline \multirow{5}{*}{$\frac{\sqrt{2}}{\frac{1}{\alpha}}$} & 6. Depressive symptoms & $.29 * * *$ & .06 & .10 & .00 & .10 & - & $.45 * * *$ & $.28 * * *$ & $.31 * * *$ & $-.14 *$ \\
\hline & 7. Illness intrusiveness & $.22 * * *$ & .03 & $.13^{*}$ & .08 & -.05 & $.50 * * *$ & - & $.36 * * *$ & $.37 * * *$ & $-.23 * * *$ \\
\hline & 8. Psychological control & $.14^{*}$ & $.31 * * *$ & .06 & -.07 & .04 & $.22 * * *$ & $.24 * * *$ & - & $.30 * * *$ & $-.33 * * *$ \\
\hline & 9. Overprotection & $.14 *$ & .07 & $.28 * * *$ & .00 & .00 & $.32 * * *$ & $.35 * * *$ & $.31 * * *$ & - & $-.13 *$ \\
\hline & 10. Treatment adherence & $-.19 * *$ & $-.23 * * *$ & $-.12 *$ & $.49 * * *$ & $-.38 * * *$ & -.11 & -.05 & $-.22 * * *$ & -.00 & - \\
\hline
\end{tabular}

Note. Above diagonal: patient-mother dyads; under diagonal: patient-father dyads.

$* p<.05 ; * * p<.01 ; * * * p<.001$. 


\begin{tabular}{|l|l|l|}
\hline Parental Functioning & Parenting & Patient Functioning \\
\hline
\end{tabular}

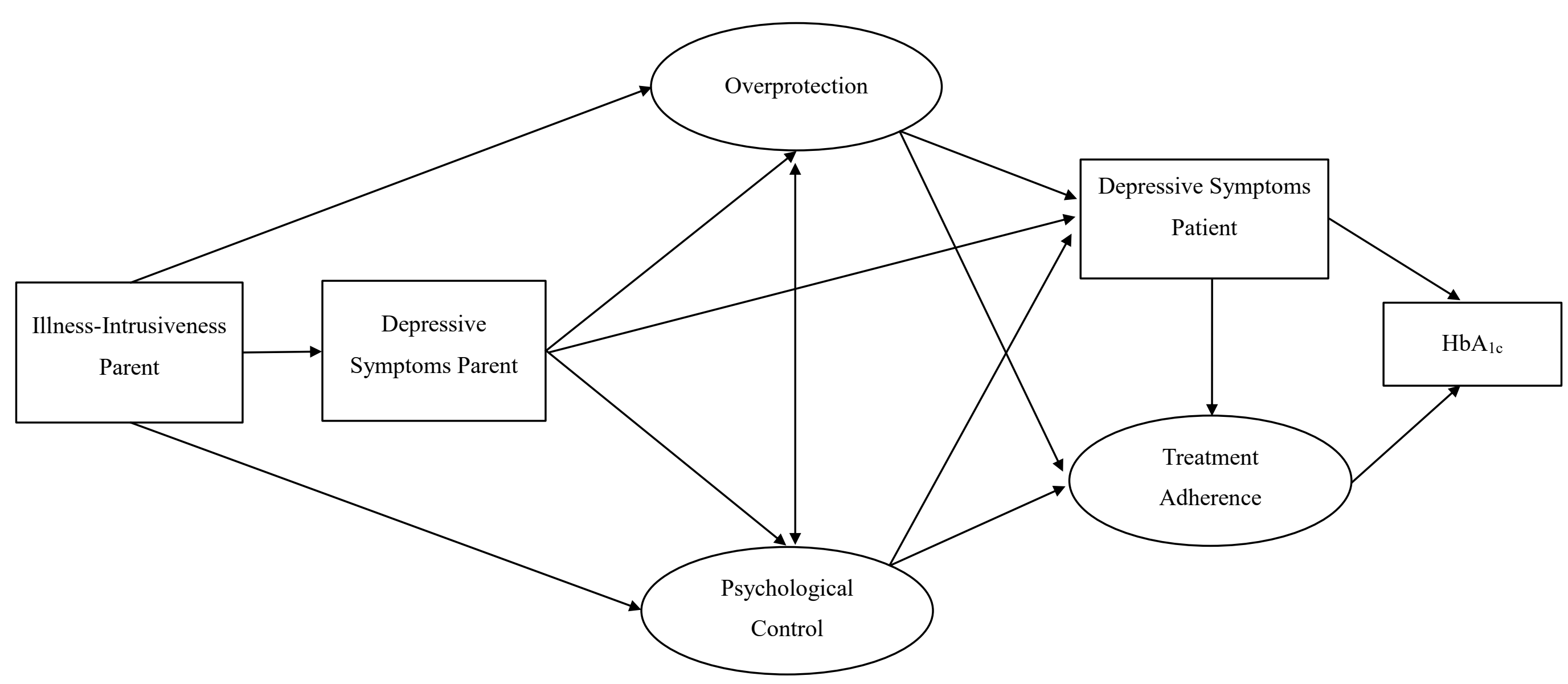

Figure 1. Parent-driven theoretical path model. Ovals represent latent constructs based on both patient and parental reports. Rectangles represent manifest constructs. 


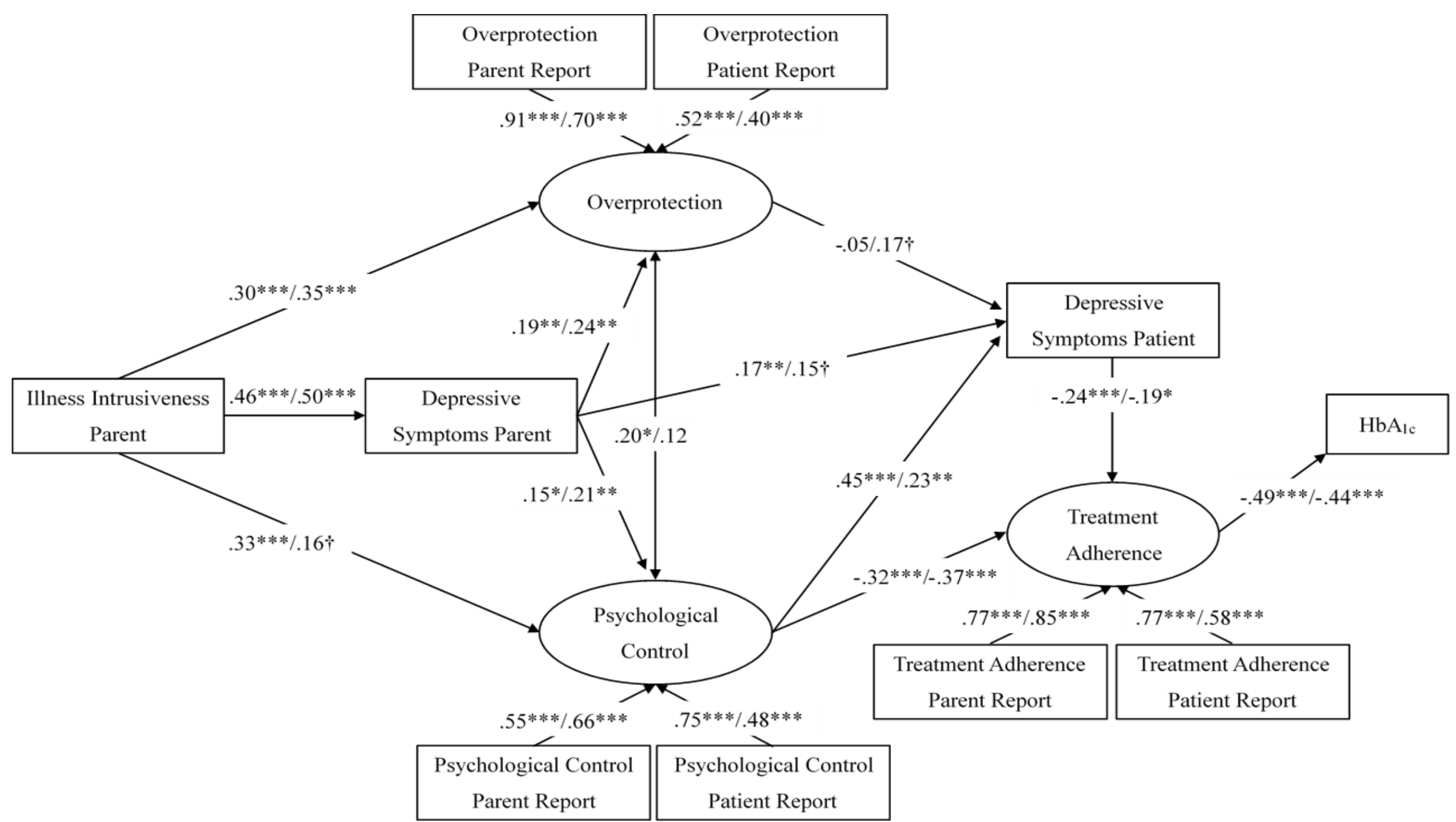

Figure 2. Results of the hypothesized path model. Associations with sex, age, insulin administration, and illness duration are not shown for reasons of clarity. Standardized coefficients are shown for patient-mother dyads before the slash and for patient-father dyads after the slash. Ovals represent latent constructs based on both patient and parental reports. Rectangles represent manifest constructs.

$\dagger \mathrm{p}<.10 ; * \mathrm{p}<.05 ; * * \mathrm{p}<.01 ; * * * \mathrm{p}<.001$. 